DOI 10.37882/2223-2974.2020.10.38

\title{
СЕКТОР НЕГОСУДАРСТВЕННЫХ ПЕНСИОННЫХ ФОНДОВ РОССИЙСКОГО ФИНАНСОВОГО РЫНКА: СОСТОЯНИЕ И ПЕРСПЕКТИВЫ РАЗВИТИЯ'
}

\section{NON-GOVERNMENTAL PENSION FUNDS OF THE RUSSIAN FINANCIAL MARKET: CURRENT STATUS AND PROSPECTS FOR DEVELOPMENT}

\section{A. Fiapshev}

Summary: The article analyzes the key aspects of the development of non-governmental pension funds of the Russian financial market. In recent decades, the dynamics of this sector was determined by the macroeconomic situation and related decisions on the development of the national pension system. The contradictory nature of these decisions led to the uneven dynamics of this sector and revealed the underestimation of the regulators' role in the development of the savings system and the financial market. Taking into account the accumulated domestic and foreign experience in regulating the sector of autonomous pension funds, its capabilities in stimulating savings and the investment process, key measures to support its development have been identified.

Keywords: non-governmental pension funds, pension savings and reserves.

\author{
Фиапшев Алим Борисович \\ Д.э.н., профессор, Финансовый университет при \\ Правительстве Российской Федерачии \\ fiapshevalim@yandex.ru
}

Аннотация: В статье проанализированы ключевые аспекты развития сектора негосударственных пенсионных фондов российского финансового рынка. В последние десятилетия динамика этого сектора определялась макроэкономической ситуацией и связанными с ней решениями по развитию национальной пенсионной системы. Противоречивость этих решений обусловили неровную динамику этого сектора и выявили недооценку регулирующих органов его роли в развитии сберегательной системы и финансового рынка. С учетом накопленного отечественного и зарубежного опыта регулирования сектора автономных пенсионных фондов, его возможностей в стимулировании сбережений и инвестиционного процесса, определены ключевые меры по поддержке его развития.

Ключевые слова: негосударственные пенсионные фонды, пенсионные накопления и резервы.
$\mathrm{H}$ епродолжительная история развития пенсионной системы Российской Федерации насыщена множеством решений, часто противоречивых и непопулярных. В то же время нельзя отрицать главную их установку на создание механизмов, способных предоставлять значимые финансовые гарантии людям, прекращающим активную трудовую деятельность. Одним из важных направлений реализации этой установки стало формирование негосударственного сегмента в этой сфере, институты которого, с одной стороны, раздели бы с государством выполнение важной миссии по пенсионному обеспечению российских граждан, а с другой стали бы активными участниками финансового рынка. Решение последней задачи было сопряжено с ориентацией деятельности этих институтов на аккумуляцию средств, высвобождаемых на более длительные сроки и, таким образом, формирующих наиболее устойчивую часть ресурсов, способных обращаться на указанном рынке. Возможность работы этих средств, составляющих важную часть накоплений граждан и имеющих выраженный, обращенный в будущее функционал, в интересах финансового рынка, всей национальной экономики, убедительно демонстрируется зарубежной практикой подобного привлечения и задействования. Обращение к отечественному опыту становления и развития негосударственных пенсионных фондов (НПФ), уже при первом приближении показывает, что двуединая задача - формирование институционально разнообразной среды пенсионного обеспечения и включение через создаваемые институты потенциально объемных пенсионных накоплений граждан в оборот финансового рынка, далека от своего решения. Причем обе стороны этой задачи очевидным образом взаимообусловлены. Проблематично в финансовом плане создать значимые гарантии для 
возрастной перспективы граждан исключительно полагаясь на распределительно-государственный механизм пенсионного обеспечения. А с другой стороны, доминирование этого механизма будет сдерживать развитие альтернативных государству институтов в этой сфере и ставить, вполне ощутимые ограничения в функционировании финансового рынка.

За последние два десятилетия пенсионная система России пережила несколько радикальных реформ. Надо признать, что и за рубежом в это время также активно реформировалась национальные пенсионные системы. Но для России этот путь был полным кардинальных решений, подчас перечеркивавших относительные успехи предыдущих этапов реформы. В 2002 году у граждан Российской Федерации появилась возможность влиять на размер будущей пенсии, до этого же времени все взносы, поступавшие в Пенсионный фонд РФ распределялись между текущими пенсионерами. Эти решения дали толчок активному формированию негосударственных пенсионных фондов - институтам нового типа в структуре отечественного финансового рынка, специально создаваемым для сбора накопительных пенсионных средств, их последующего инвестирования и выплат работникам из их дополнительных пенсий.

Была сформирована и поступательно развивалась нормативно-правовая регламентация деятельности НПФ. Сегодня она регулируется целым рядом законов, в том числе устанавливающих перечень инструментов, в которые эти институты могут размещать пенсионные средства. С 2016 года все негосударственные пенсион- ные фонды обязаны были вступить в систему гарантирования пенсионных накоплений. Тем самым была реализована попытка обеспечить сохранность пенсионных накоплений российских граждан.

Российская экономика сегодня остро, впрочем как и во многие предыдущие периоды своей истории, нуждается в дополнительных инвестициях. Эта потребность усиливается ограниченным притоком иностранного капитала в национальную экономику. И в этих условиях пенсионные накопления, грамотное управление ими могут стать важным фактором снижения остроты этой проблемы.

Сегодня сектор негосударственных пенсионных фондов представлен главным образом в крупными фондами, контролирующими более 70 \% аккумулированных в этой отрасли денежных средств, на них же приходятся такие же доли пенсионных взносов и участников соответствующей системы. На рисунке 1 представлены данные о количестве негосударственных пенсионных фондов. Видно, что для этого сектора также, как и для многих других на отечественном финансовом рынке, характерна убывающая динамика количества институтов, в итоге усиливающая процессы концентрации и централизации.

Совокупный портфель пенсионных средств к исходу 3-го квартала 2019 г. превысил 6 трлн руб., что составило 5,6\% ВВП. Инвестиционный портфель пенсионных средств НПФ достиг 4,2 трлн руб., из которых 2,8 трлн руб. пришлось на пенсионные накопления и 1,4 трлн руб. - на пенсионные резервы. Кроме того, количество

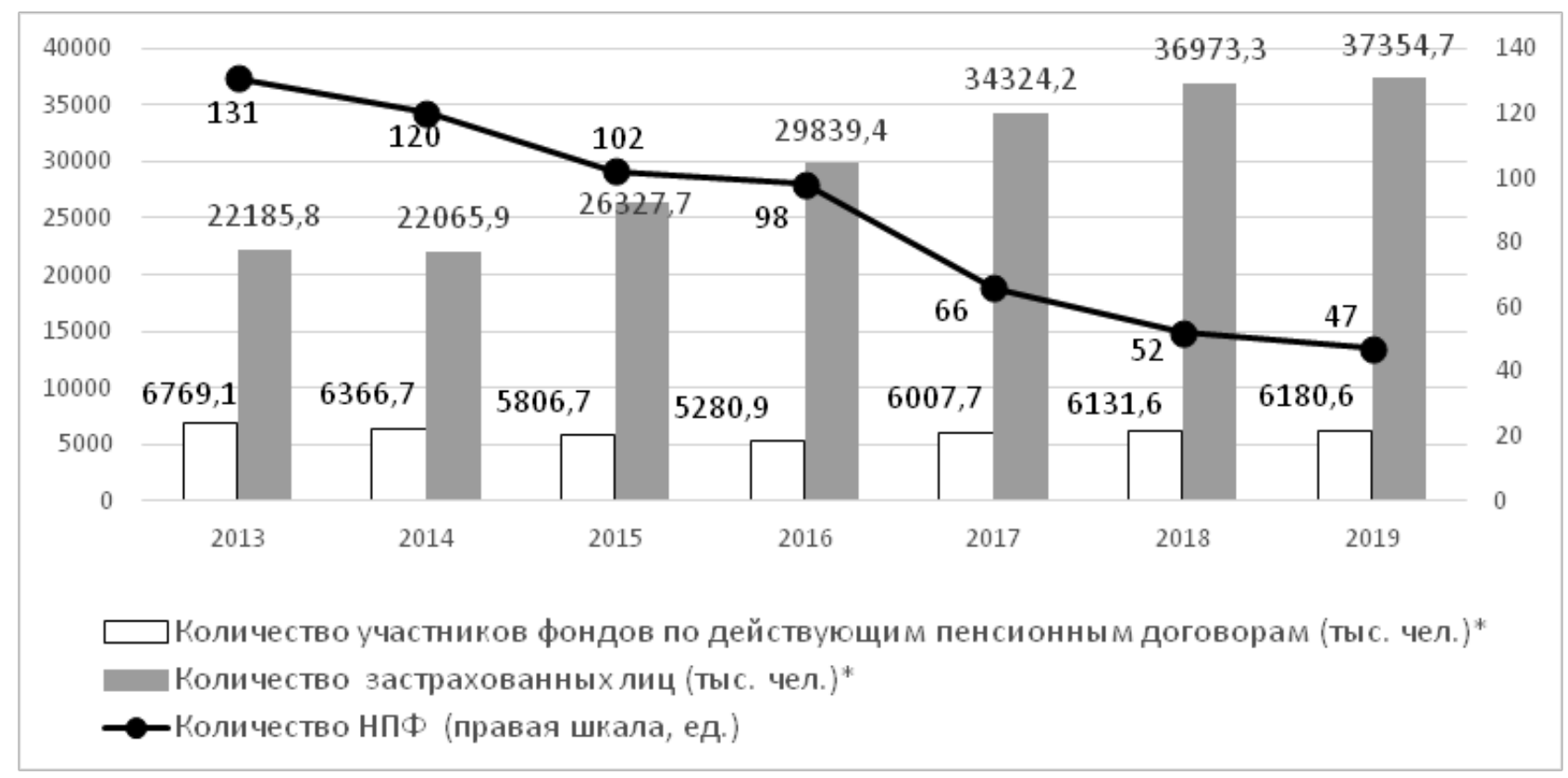

Рис. 1. Отдельные количественные показатели развития НПФ

* Данные для 2019 г. приведены за девять месячев

Источник: Банк России 
участников фондов по действующим договорам страхования не восстановилось до докризисного уровня, что является общим для большинства секторов отечественного рынка. В то же время число застрахованных лиц имеет выраженную склонность к увеличению. Этот процесс можно рассматривать как результат запрета на принятие решения о формировании накопительной пенсии после 2015 г., спровоцировавший увеличение интереса со стороны населения к негосударственным пенсионным фондам. В качестве одной из причин можно также рассматривать традиционно недостаточно привлекательную для многих доходность, которую показывала государственная управляющая компания Внешэкономбанк по этим операциям. Однако, интерес населения к участию в добровольной пенсионной системе в течение 2019 г. практически не увеличил сся. Так, рост пенсионных резервов находился в течение 3-го квартала этого года на уровне предыдущих соответствующих временных отрезков. При этом число участников не изменилось.

Данная картина дополняется информацией о других показателях деятельности НПФ. Она представлена данными рисунка $2[1,2]$.

Доля активов негосударственных пенсионных фондов в валовом внутреннем продукте Российской Федерации за анализируемый период с 2013 г. по 2019 г. выросла до 4\% (рисунок 3). В этом же тренде находились изменения отношения пенсионных накоплений фондов к ВВП, что нельзя сказать о пенсионных резервах.
При этом стоимость активов пенсионных фондов к ВВП в странах ОЕCD составляла в 2016 г. в среднем около 40\%, а во многих развитых странах этот показатель находился на несоизмеримо более высоком уровне. В Германии - 17\%, Японии - 32\%, Канаде - 90\%, Исландии, Нидерландах, США, Швейцарии - более 100\%. В сравнении с развивающимися рынками, в том числе стран BRICS, Россия по этому показателю находится отнюдь не в замыкающей группе государств. Так, среди стран BRICS она уступает лишь Бразилии с ее закрытыми фондами, при этом заметно превосходит Китай и Индию, где значения показателя отношения активов автономных пенсионных фондов к ВВП находятся соответственно на уровнях 1,4 и 0,8 \%. Для этих стран пока характерен недостаточно высокий уровень развития пенсионных накоплений [3].

При всем при этом именно по этому сектору, демонстрировавшему устойчивую и положительную динамику до 2013 г. российским государством был нанесен болезненный удар в виде замораживания системы пенсионных отчислений. Принятые решения показали, сектор НПФ находится на периферии государственных приоритетов развития финансового рынка. В это же время на цели финансовой поддержки крупных российских банков, пострадавших в результате кризиса было потрачено более 1,5 трлн рублей. И, как показала последующая практика, значительная часть этих средств была списана на убытки национального регулятора, покрывшиеся в результате покупки российским правительством у центробанка пакета акций Сбербанка за счет ресурсов, накопленных в Фонде национального благосостояния. По

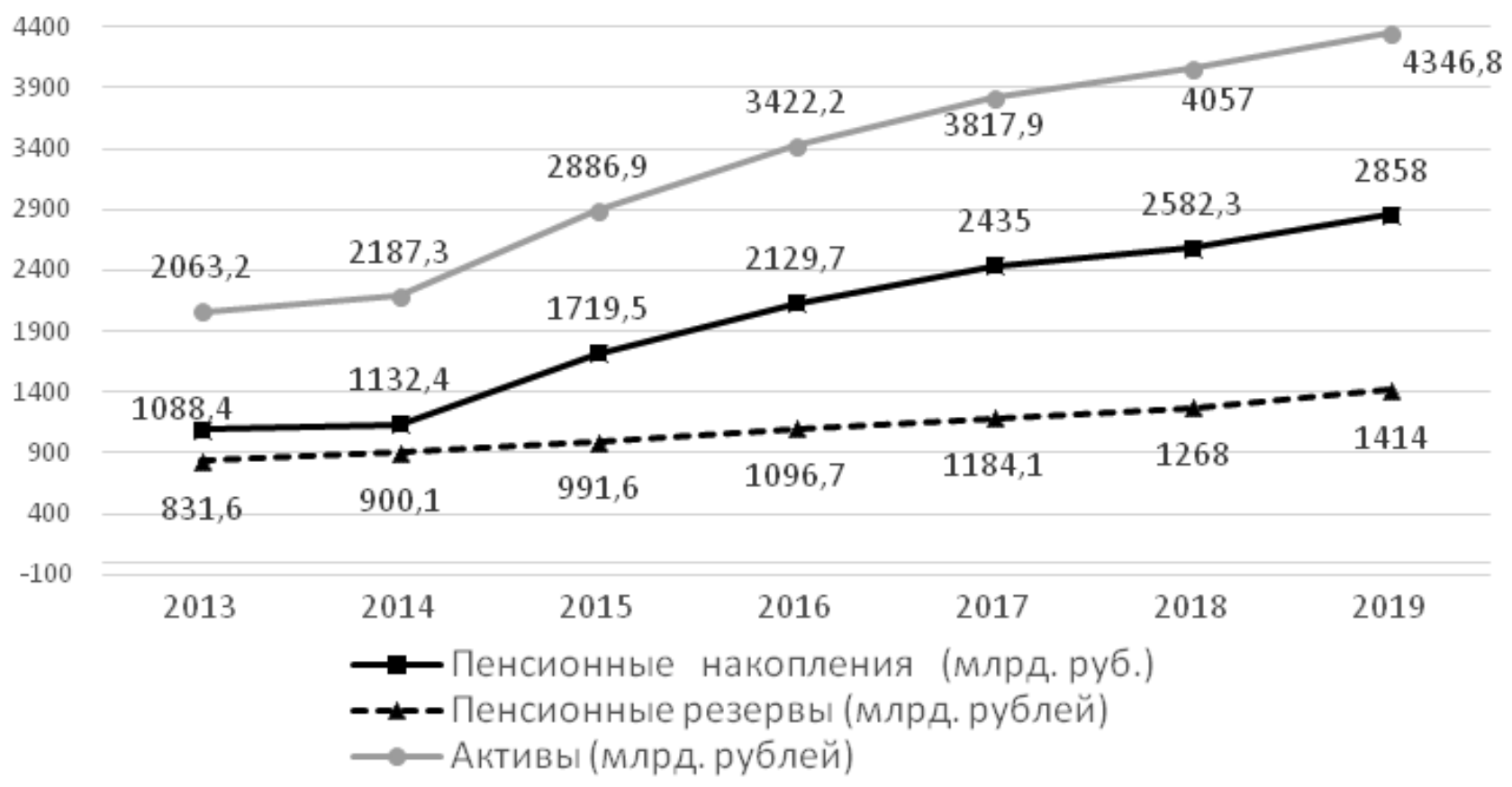

Рис. 2. Динамика активов, пенсионных накоплений и пенсионных резервов НПФ Источник: Банк России 
оценкам экспертов, только за последующие три года, последовавшими за принятыми решениями о замораживании пенсионных накоплений, НПФ и управляющие компании недополучили около одного триллиона рублей [4].

Рассматривая негосударственные пенсионные фонды как экономических агентов, решающих задачу оптимизации инвестиционного процесса на долгосрочном периоде, стоит отметить, что важнейшей установкой их деятельности является получение дополнительных финансовых ресурсов от инвестирования аккумулированных средств участников НПФ в высокодоходные активы. Реализуя более агрессивную, часто спряженную с более высокими рисками, инвестиционную стратегию этот сектор, не взирая на сопутствующие его развитию неблагоприятный фон, с каждым годом отвоевывал все большие позиции у Пенсионного фонда России. Речь идет о сдвигах в структуре пенсионных накоплений в сторону увеличения доли негосударственного сектора.

С середины 2017 г. НПФ последовательно повышали качество своих портфелей, что было связано с необходимостью прохождения стресс-тестирования. С этого же времени значительное число НПФ начали показывать отрицательные результаты инвестирования. В 2019 г. произошел разворот тенденции, выразившийся в том, что автономные фонды вновь показали более высокие резульлтаты инвестирования, чем государственная управляющая компания. Рост доходности НПФ был связан с увеличением доли долговых инструментов. При всем при этом 45\% частных фондов продолжали демон- стрировать доход ᄀность не ниже ВЭБ три года подряд и на них пришлось более половины пенсионных накоплений и застрахованных лиц НПФ. Таким обралзом, несмотря на отставание средневзвешенного значения, доходность по пенсионным накоплениям значительной доли лиц, застрахованных в НПФ, опережало значение государственной управляющей компании все эти годы. Средневзвешенная доходность от размещения пенсионных резервов в течение большей части 2019 г. оставалась на уровне ниже доходности по пенсионным накоплениям, 8,2\% против и 10,1\%. Это было связано с меньшей долей долговых инструментов в инвестиционном портфеле пенсионных резервов НПФ. В то же время последние минимизируют риски свои риски и в этом отношении их деятельность имеет свою специфику [5].

В то же время, при всей увеличивающейся роли небанковского финансового сектора в структуре отечественного финансового рынка, относительно сбалансированной и устойчивой деятельности, показанной НПФ в последние годы, потенциал этих институтов, как важных участников рынка, явно недооценен. Этому не способствовала и государственная политика в пенсионной сфере. Доверие значительной части населения как к этой политике, так и негосударственным институтам, оказавшимися такими же заложниками принятых решений, как и российские граждане, существенно подорвано. Отчасти об этом можно судить по данным о доле инвестиционных портфелей по пенсионным накоплением и резервам в российском ВВП (рисунок 4). Эти отношения заметно, а в ряде случаев значительно ниже не толь-

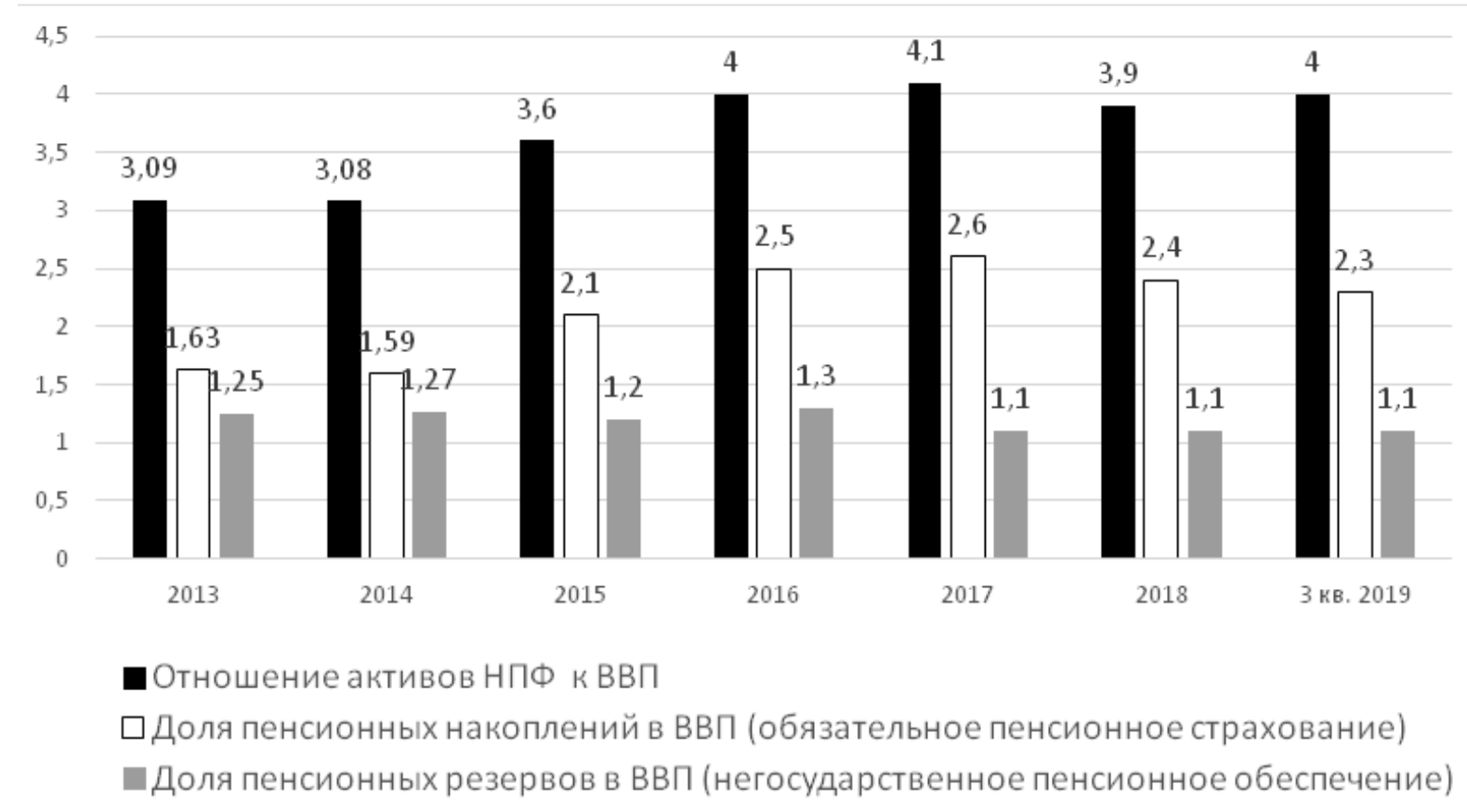

Рис. 3. Отношение активов, пенсионных накоплений и пенсионных резервов НПФ к ВВП России, \% Источник: Банк России 
ко в сравнении с развитыми странами, но и странами, еще недавно входившими в союзное государство. Кроме того, видно, что даже на фоне незначительно увеличивающего ВВП, эти соотношения не только не меняются, но и снижаются. Впрочем, макроэкономическая динамика и развитие финансового рынка, в том числе в этой его части, процессы взаимообусловленные.

О дефиците доверия к финансовому рынку, главным образом его небанковским секторам, и инструментам, обращающимся на них, говорит и регулятор в Основных направлениях развития финансового рынка [6]. Но решение этого вопроса выходит за рамки собственно, проблематики развития самого этого рынка, и, очевидно, будет являться результатам реализации более общих мер в области экономической политики, также политики в области предоставления российским гражданам социальных гарантий. Тем не менее, речь ниже пойдет о рекомендациях, направленных, при прочих равных условиях, на повышение привлекательности автономных пенсионных фондов как важных участников небанковского сегмента финансового рынка, ориентирующих свою деятельность на сбережения населения. Достижение этой цели связывается не только с превращением этого сегмента в эффективный механизм капиталообразования, но и приумножением частных сбережений - решением по сути своей важной социальной проблемы. Важными условиями для этого могут стать:

- повышение доверия населения к финансовому рынку и к государству как гаранту исполнения заколнодательства;

- повышение уровня защиты прав и законных интересов инвесторов;

- развитие системы добровольных пенсионных накоплений, включая закрепление права собственности в отношении пенсионных накоплений за будущими пенсионерами;

- активное проведение приватизации государ- ственных предприятий и пакетов акций, с задействованием механизмов, исключающих концентрацию собственности, и способствующих росту конкуренции в экономике;

- ориентация на передовые зарубежные практики в сфере обеспечения прозрачности информации о финансовых инструментах и продуктах для принятия инвестиционных решений.

Отечественными экспертами к настоящему времени наработан обширный пакет рекомендаций по стимулированию небанковского финансового сектора и в рамках него сегмента функционирования автономных пенсионных фондов. Совокупность этих рекомендаций очерчивает несколько возможных альтернатив перспектив развития упомянутого сектора. Одной из них является альтернатива, реализация которой сопряжена с активизацией притока сбережений населения на небанковский финансовый рынок, и не в последнюю очередь в негосударственные пенсионные фонды [3]. Такая возможность связывается как с общим повышением объема сбережений населения без существенных изменений их структуры, так и с улучшением их структуры. В любом случае ее реализация сопряжена с нормализацией инвестиционного климата, устойчиво позитивной макроэкономической динамикой, а также при соблюдении этих условий повышением результативности просветительских мер в части перспектив финансового рынка. Любые другие условия и меры, реализуемые при не меняющемся макроэкономическом фоне и направленные на изменение соотношения между потреблением и сбережением расцениваются как контрпродуктивные. Кроме того, изменение структуры сбережений населения в пользу инструментов финансового рынка, используемых при содействии автономных пенсионных фондов, предполагает устранение в рамках регуляторной практики дискриминации небанковского финансового сектора по сравнению с банковской системой.

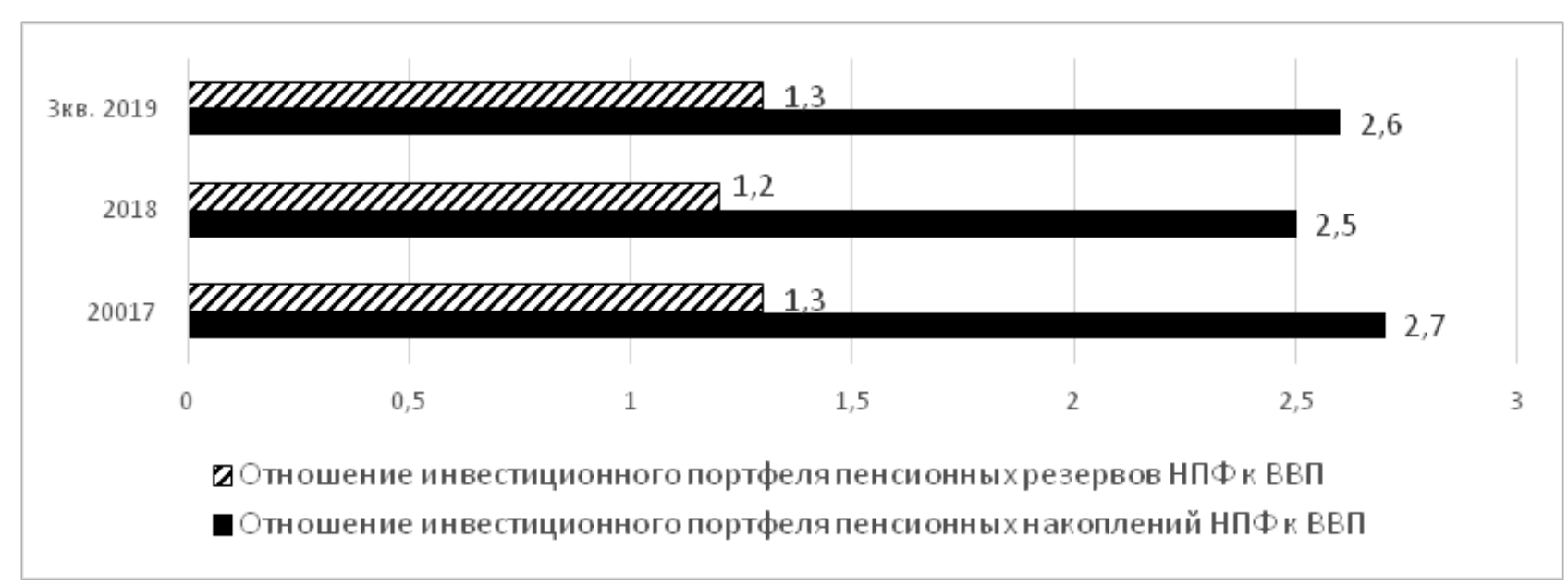

Рис. 4. Отношения инвестиционных портфелей пенсионных накоплений и резервов к ВВП России, \% Источник: Банк России 
Таким образом, весь комплекс условий, обеспечивающих результативное решение проблем активизации деятельности негосударственных пенсионных фондов как участников небанковского финансового сектора на рынке сбережений можно разбить на две группы. Первую группу составляют внешние условия по отношению к деятельности НПФ, носящие обязательный (необходимый) характер. Среди них:

1. Совершенствование государственной политики в области пенсионного обеспечения граждан, предполагающее обеспечение ее полномасштабной транспарентности, построение четкой иерархии целей и обеспечение определенности в их эшелонирования во времени. Обеспечение обязательности и точности реализации декларируемых реформационных действий, стратегическое планирование.

2. Улучшение инвестиционного климата и институтов, являющееся условием эффективности мер по защите интересов инвесторов и прав потребителей финансовых услуг.

3. Сокращение доли государства в экономике, создающее необходимые условия для роста ее финансовой глубины и конкуренции.

Применительно к реформе небанковского финансоволго сектора, и сегмента, охватывающего деятельность автономных пенсионных фондов, перечисленные меры отнюдь нельзя считать исчерпывающими. Но, тем не менее их реализация, как представляется, закладывает необходилмые условия, при которых становятся возможны реформы уже в самом сегменте НПФ. Состояние, в котором сегодня находится этот сегмент, делает невозможным повышение его эффективности в части работы со сбережениями граждан, имеющими выраженный и обращенный в будущее функционал, без существенного изменения этих условий.

Внешние обстоятельства формируют необходимые условия для результативной деятельности негосударственных пенсионных фондов. Их достаточность достигается самой их деятельностью, основными задачами которой являются обеспечение сохранности и возвратности пенсионных ресурсов и их защита от инфляции в долгосрочном периоде. Их решение обусловливает необходимость правильного структурирования инструментов для инвестиций и обеспечение грамотного управления активами. Это в свою очередь может изменить мотивы сберегательного поведения граждан, в большей мере сориентировать их на долгосрочные интересы, обеспечиваемые деятельностью пенсионных фондов, в том числе функционирующих на автономных началах.

Кроме этого, приватизация государственной собственности существенно бы расширила финансовый рынок, дала бы ему толчок, включив в его орбиту новые объекты для инвестирования. Вкладывая привлекаемые ресурсы в приватизационные активы, НПФ могут стать ключевым источником долгосрочных вложений в экономику России. Тем самым, они решат и многие свои ресурсы, нарастят портфели, привлекут новых участников. Очевидно, что решения в этом направлении имеют не только экономическую, но и выраженную социальную подоплеку. Анализ зарубежной практики в этой части со всей убедительностью демонстрирует выгодность таких решений для всех участников данного процесса. Использование длинных пенсионных денег в качестве вложений в акции компаний, котирующихся на бирже (IPO, SPO), является привлекательным и доходным инструментом. Негосударственные пенсионные фонды являются одним из важнейших игроков на финансовом рынке России и в условиях экономического кризиса выполняют важную социальную миссию, способны также сыграть значимую роль в инвестировании в реальный сектор российской экономики.

Таким образом, сегмент негосударственных пенсионных фондов отечественного финансового рынка, несмотря на целый комплекс неблагоприятных обстоятельств, сопутствовавших развитию российской экономики и целый ряд непопулярных и противоречивых государственных решений в пенсионной сфере, продемонстрировал свой весомый потенциал. Накопленная доходность НПФ в последние годы превысила инфляцию и доходность государственной управляющей компании ВЭБ. В то же время пенсионные накопления не рассматриваются регулятором как важный источник долгосрочного инвестирования субъектов экономики. Показатели активов, инвестиционных средств и портфелей негосударственных пенсионных фондов, приведенных к значениям национального ВВП остаются на низком уровне. Вместе с тем, зарубежная практика убедительно опровергает скепсис относительно роли, которую могут играть НПФ в инвестиционном процессе, развитии сберегательной системы и решении социальных задач.

Среди мер, способных оказать позитивное воздействие на функционирование сегмента НПФ, превратить его в значимый фактор продуцирования инвестиций на длительном горизонте, можно выделить также следующие: постепенное вытеснение накопительным механизмом распределительного, основанного на солидарном принципе; поступательная активизация участия работников в финансировании пенсионного обеспечения на основе приближения к пропорции 50:50 работодателей и работников в финансировании будущей пенсии; определение обоснованных пропорций инвестирования средств пенсионных фондов между внутренним и внешним рынком через законодательное установление так называемой нормы международной диверсификации пенсионных накоплений. 


\section{ЛИТЕРАТУРА}

1. Обзор ключевых показателей негосударственных пенсионных фондов. Информационно-аналитический материал. URL: https://www.cbr.ru/analytics/ RSCl/activity_npf/\#a_85256 (Дата обращения: 15.06.2020).

2. Тенденции рынка НПФ. IV квартал 2019 года. URL: https://www.cbr.ru/Collection/Collection/File/27274/NPF_market_trends_2019-q4.pdf (Дата 06ращения: 15.06.2020).

3. Корищенко К.Н., Абрамов А.Е. Влияние негосударственных пенсионных фондов на экономический рост / Заключительный отчет научно-исследовательской работы. URL: http://pensionreform.ru/files/117278 (Дата обращенияа: 15.06.2020).

4. Данилов Ю.А., Буклемишев 0.В., Абрамов А.Е. 0 необходимости реформы финансовых рынков и небанковского финансового сектора. Вопросы экономики. 2017(9); 28-50.

5. Травкина Е.В. Факторы, обуславливающие необходимость проведения мониторинга рисков российского банковского сектора. Финансы и кредит. 2013(1);29-33.

6. Основные направления развития финансового рынка Российской Федерации на период 2019-2021 годов. URL: https://www.cbr.ru/Content/Document/ File/71220/main_directions.pdf (Дата обращения: 15.04.2020).

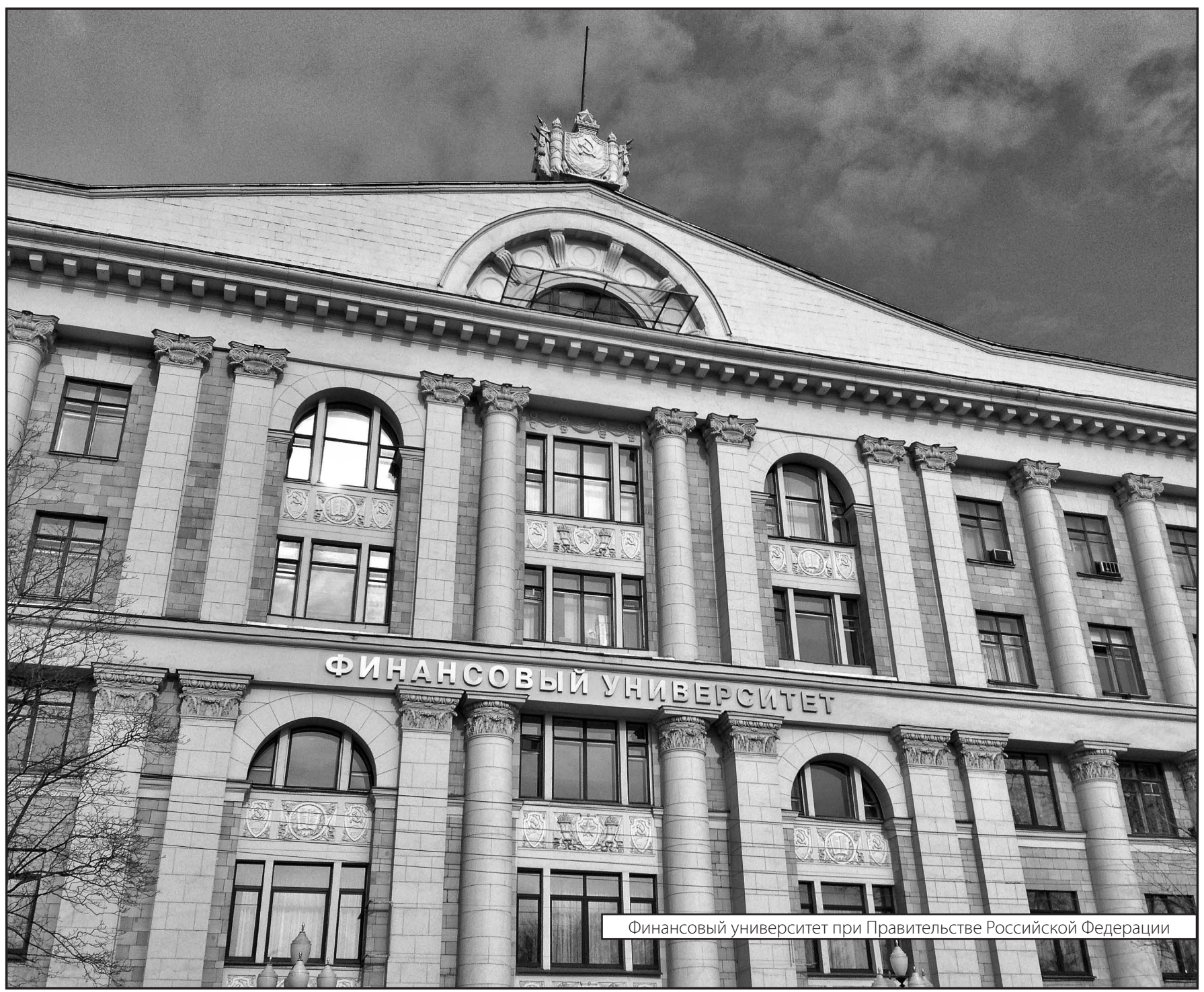

